\title{
Mapping Maternal Health in the New Media Environment: A scientometric Analysis
}

Yinghua Xie ${ }^{1}$, MLIS; Dong Lang BBA ${ }^{1}$;Chengxu Long², PhD; Shangfeng Tang ${ }^{1}$, PhD ${ }^{1}$ School of Medicine and Health Management, Tongji Medical College, Huazhong University of Science and Technology, Wuhan, China

${ }^{2}$ Department of Global Health \& Social Medicine, King's College London, London, United Kingdom

\section{Corresponding Author:}

Shangfeng Tang, PhD

School of Medicine and Health Management

Tongji Medical College

Huazhong University of Science and Technology

13 Hangkong Road

Wuhan

China

Phone: 8613349895639

Email: sftang2018@hust.edu.cn

\begin{abstract}
Background: The new media provides a convenient digital platform to access, use and exchange health information. As a special group of health care, maternal is still of international concern due to their high mortality rate. Improving maternal health as a Millennium Development Goal of the United Nations is an important quest for the health care system. Scientific research provides advice on how to improve maternal health through stringent reasoning and accurate data. However, the dramatic increase of publications, the diversity of themes, and the dispersion of researchers may reduce efficiency.
\end{abstract}

Objective: This study aims to analyze the research progress on maternal health under the global new media environment, exploring the current research hotspots and research frontiers.

Methods: A scientometric analysis was carried out by CiteSpace5.7.R1, searching in the core database of Web of Science for articles published in English from 1998 to 2021, and combined topic words such as new media, maternal, and health. In total, 3312 articles have been retrieved, of which 2270 studies have been included for further analysis. Top countries and institutions, potentially high-impact literature, research frontiers, and hotspots were analyzed in this study.

Results: The number of publications grew rapidly after 2008, from 29 publications sharply increasing to 472 publications by 2020 . Research centers concentrated in Latin America, such as the University of Toronto, the University of California. The work of 
Larsson M, Lagan BM, Tiedje L, and Helle C had a high potential impact. Most of the research subjects were maternal and newborn babies, and the research frontiers focused on health education and maternal psychological problems. Maternal mental health, maternal and infant nutrition, weight, production technology, and equipment were hotspots.

Conclusion: The development of new media has brought a new era for maternal health, characterized by psychological qualities, healthy and reasonable physical conditions, and advanced technology.

Keywords: maternal health; new media; bibliometric analysis; cited reference analysis; structural variation analysis; hot spots 


\section{Introduction}

The World Health Organization defines maternal health as women's health care during pregnancy, childbirth, and postpartum. However, more than half a million women die each year from pregnancy-related causes globally, mostly in developing countries[1]. Therefore, improving maternal health was proposed as one of the United Nations Millennium Development Goals to reduce maternal and infant mortality[2]. Governments worldwide responded positively, not only by issuing a series of policies but also by launching some national actions. Several countries have implemented free maternal health policies, such as Laos and Nepal[3,4]. Maternal healthcare was enrolled in essential public health services in China and Cambodia[5,6]. Maternity hospitals in Uzbekistan and Kyrgyzstan have skilled obstetric attendants to provide maternal services[7]. Brazil promulgated respectively National Programme in 2000 and 2004, aiming at improving maternal health and reduce the mortality rate of newborns[8].

Some progress has been made in maternal health in academic $[5,9,10]$, for instance, making thorough inquiries in the factors affecting the utilization of health services [11] and the association between maternal and infant health[12]. Nonetheless, the rapid development of new media environment has provided convenience to find health information[13]. According to the data of Internet World Statistics (IWS), in the first quarter of 2021, there were 7.8 billion Internet users worldwide, accounting for $65.6 \%$ of the world's population[14]. As an important intermediary for the public and health professionals to communicate, the new media environment also provide a new dimension for improving health levels and the effectiveness of medical care[15]. Of course, it also provides convenience for scientific research to obtain the required data[16]. Moreover, the application of mobile devices in health is conducive to enriching maternal health knowledge and improving health services utilization[17-19]. However, studies have also shown that new media environment have certain risks compared to traditional interventions for maternal health[20].

At present, a few publications focuses on the research status of new media or pregnant women health with scientometric methods, while there is no literature in structural variation analysis to explore the impact of new media environment on maternal health. So it is necessary to adopt this method to clarity under the new media environment on maternal health research trend and hotspots, bridging this gap. CiteSpace, a well-known scientometric software characterized by vitality and intuition, is widely used in various specific research fields[21]. Therefore, this study will use CiteSpace5.7.R1 to analyze about maternal health in the new media environment, aiming at understanding the research status and summarizing the current hot topics, and laying a solid foundation for improving maternal health and further research work. 


\section{Methods}

\subsection{Recruitment}

We defined the topic of this study as maternal health in the context of new media. We extracted three keywords in exploring specific definitions: pregnant women, new media, and health. By reading the previous literatures, we preliminarily determined several definitions about pregnant women, which helps us understand pregnant women's complicated nature. Besides, this study enriches and improves the expressions of synonyms by using MeSh Browser. Paralleling with operating the concept of pregnant women, we also use a substantial array of new media platforms as part of the search strategy. Overall, The search strategy combines free-text terms such as maternity, health, and new media platforms: "TS= ('pregnant woman' OR 'expectant mother' OR 'lying-in woman' OR puerpera OR 'pregnant and lying-in woman' OR parturient OR 'delivery woman' OR puerperal OR primipara OR 'woman expecting confinement' OR 'gestational woman' OR gravida OR maternal OR 'pregnant and birthgiving woman') AND TS = (Online OR 'social media' OR web OR virtual OR cyber OR Orkut OR Twitter OR Facebook OR Reddit OR Instagram OR Snapchat OR youtube OR Whatsapp OR WeChat OR QQ OR Tumblr OR Linkedin OR Pinterest) AND TS $=($ health*)."

Owing to the remarkable interdisciplinary characteristics of the subjects, thus the research topics closely related to medics and medicine, we choose the most widely used [22] the core database of Web of Science as the data source in many databases. Generally, articles were cited more frequently than other studies, and were second only to meta-analysis, but also gave new research conclusions[23]. For clarity on research status about maternal health for nearly 20 years in the new media environment, therefore we systematically searched the articles in the core database of Web of Science between January 1998 and May 2021. Finally, 3312 studies were entered in CiteSpace for quantitative analysis, aiming to understand the research trends, summarize the current research hotspots and frontiers on maternal health in the new media environment. The data retrieval and selection process is shown in Figure 1. 


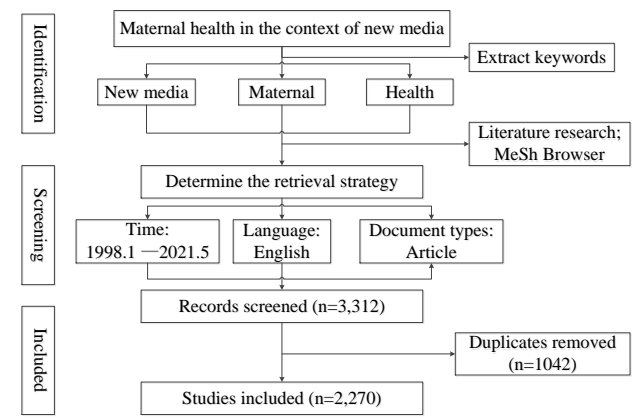

Figure 1. Flow diagram of data search and selection

\subsection{Mapping the Knowledge Map}

As a combination of science and art, knowledge maps help us detect the structure of knowledge about a specific area. CiteSpace is facilitated to reveal the structure and dynamics of a knowledge domain graphically. In this study, CiteSpace V. 5.7.R1(64bit) was used for scientometrics analysis. Firstly, 3312 studies retrieved from the Web of Science core database were imported into CiteSpace. After removing duplicates, a total of 2270 studies were eventually included in further analysis. The specific parameters were set as follows: The time slice was set as three years, then the study period was divided into nine partitions. Term source consists of titles, abstracts, and keywords. The connection strength is set as cosine. The node threshold value is "Top50", that is, each slice consists of 50 documents with the highest citation frequency. Network pruning is allowed, selecting "Pruning path." The visual view mainly selects co-occurrence view, static clustering view, and timeline view. We successively analyzed the top countries, institutions, cited references, and keywords about maternal health research in new media environment, aiming to explore the current research frontiers and hotspots.

In the co-occurrence view, the node's size indicates the frequency of occurrence of fields (such as country, institution, keyword). The color of the node (citation ring) represents the field's history. The thickness of the color and the corresponding time is proportional. The color changes from cold to warm. The line between nodes represents the relationship between nodes. Moreover, the thicker the line, the closer the relationship is. Most importantly, centrality could predicts transformative changes, which is more valuable than frequency. The calculation of centrality is as follows[24]: $B C_{i}=\sum_{s \neq i \neq t} \frac{n_{s t}^{i}}{g_{s t}}, g_{s t}$ is the number of shortest paths from $\mathrm{S}$ to $\mathrm{T}$, and $n_{s t}^{i}$ is the number of shortest paths passing through node I in $g_{s t}$. In general, emerging scientific discoveries will have high centrality[25]. Nodes with purple circles have higher centrality $(\geq 0.1)$, and the thicker purple aperture indicates more important. In addition, burst detection could visually reflect the rise and fall of a particular subject in CiteSpace[26]. In the cluster view, the smaller the cluster number is, the larger the cluster is. The clustering color is consistent with the clustering label color. The timeline 
view could reflect the clustering results and visually compare the period of clustering duration. Every literature or keyword with a high burst represents a breakthrough in the existing network structure, and the red color represents the duration period of the burst.

\section{Results}

\subsection{Publications Analysis}

Research on maternal health in the new media environment started in 1998 and declined until 2020, with the publications and citation activities increasing over the year. Nevertheless, the growth is different, which could be divided into two stages. From 1998 to 2007, the number of publications and citation activity was relatively small, with relatively slow growth. There was steady and rapid growth in publications and citation activities between 2008 and 2020. The number of 472 publications in 2020 was more than 16 times in 2008, showing remarkable ascend (Figure 2).

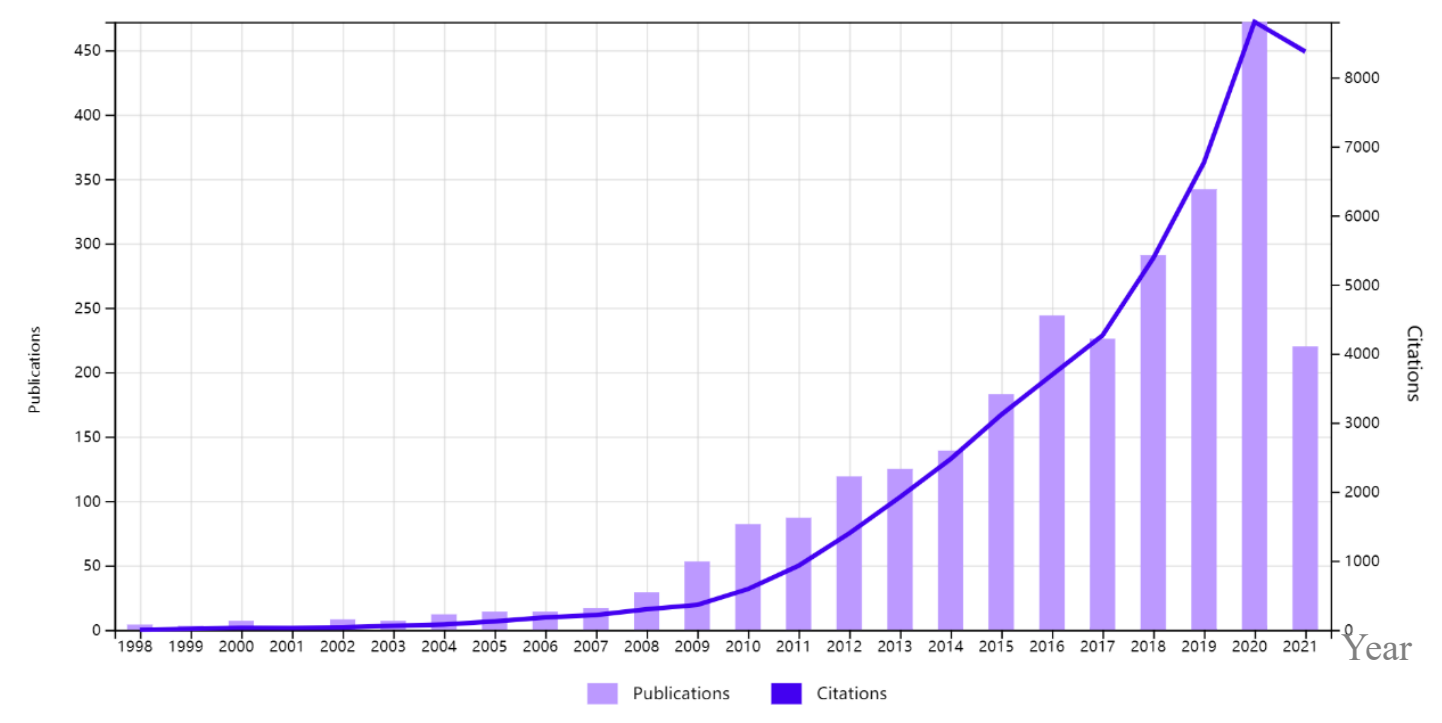

Figure 2. Times Cited and Publications from 1998 to 2021

\subsection{Top Country and Institution}

The 2270 articles on maternal health research in the new media environment were published by research groups in 72 countries (Figure 3). The top 10 countries (five located in Europe, three in American, one in Asia, and Australia) published 2184 articles, accounting for $96.21 \%$ of the total number of publications. The United States had the most significant number of publications, with 905 publications, accounting for $39.87 \%$. Followed by Australia, The United Kingdom, Canada and the Netherlands. China had published 84 papers in this field, accounting for $3.70 \%$, ranking sixth. In this 
research field, the United States kept close cooperation with the United Kingdom, So are Australia and Canada. At present, this field has three significant clusters totally.

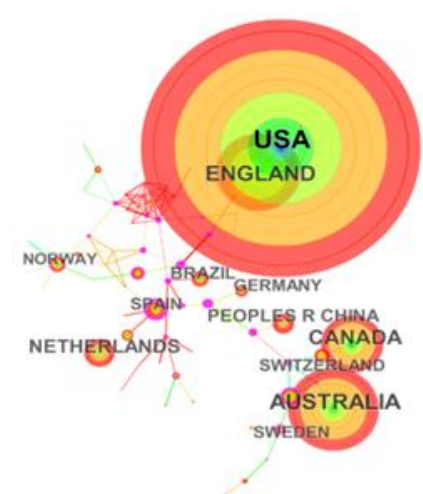

Figure 3. Collaborative networks based countries

The 2270 articles were published by 148 research institutions (Figure 4). The whole network was in a state of non-connectivity, with a network density of only 0.0155. The leading institutions were in America, including the University of Toronto, University of California, University of North Carolina and University of British Columbia, University of Michigan. And then university systems also located in Australia, including the University of Monash, University of Queensland, and the University of Technology Sydney. Notably, the quality of articles, namely the importance of publications, could not be ignored in scientometrics analysis. Among all institutions, Eunice Kennedy Shriver Natl Inst Child Hlth \& Hum, the University of North Carolina at chapel hill, WHO, University of NottinghamStan Stellenbosch university in centrality were more significantly 0.3 , indicates that these universities played crucial roles in promoting research cooperation. The frequencies of publications by the top 10 countries and institutions are presented in Table 1. 


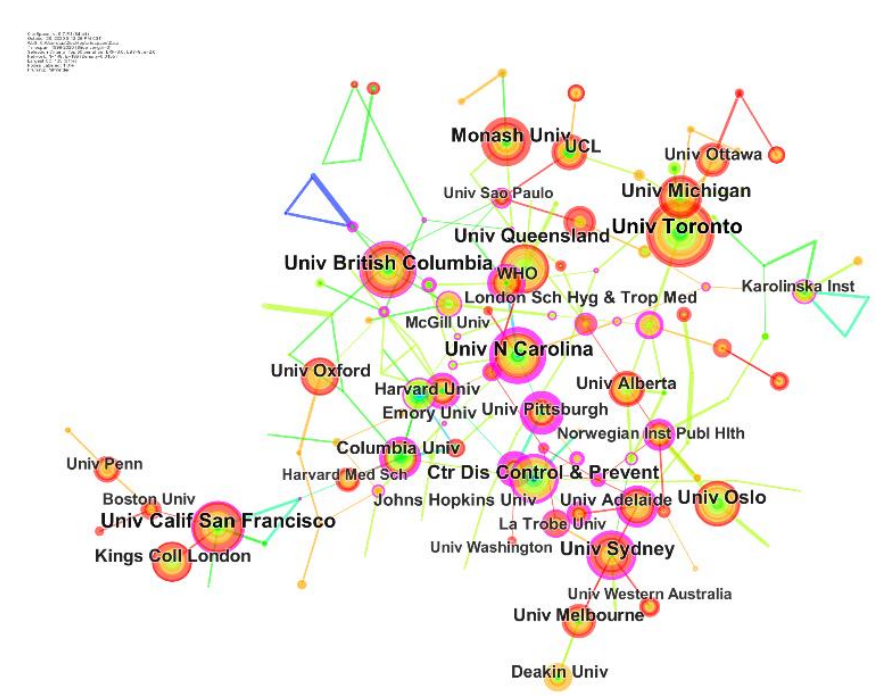

Figure 4. Collaborative networks of institutes

Table 1. Top countries, institutes according to the number of publications

\begin{tabular}{|c|c|c|c|c|}
\hline Ranking & Frequency & Country & Frequency & Institution \\
\hline 1 & 905 & $\begin{array}{l}\text { The United } \\
\text { States }\end{array}$ & 52 & University of Toronto \\
\hline 2 & 305 & Australia & 42 & University of California \\
\hline 3 & 277 & $\begin{array}{l}\text { The United } \\
\text { Kingdom }\end{array}$ & 41 & University of North Carolina \\
\hline 4 & 216 & Canada & 38 & University of British Columbia \\
\hline 5 & 121 & Netherlands & 37 & University of Monash \\
\hline 6 & 84 & China & 34 & University of Queensland \\
\hline 7 & 76 & Brazil & 34 & University of Oslo \\
\hline 8 & 68 & Switzerland & 34 & University of Michigan \\
\hline 9 & 67 & Spain & 34 & $\begin{array}{l}\text { US Center for Disease Control and } \\
\text { Control }\end{array}$ \\
\hline 10 & 65 & Sweden & 30 & University of Technology Sydney \\
\hline
\end{tabular}

\subsection{Cited Reference Analysis}

In the bibliometric analysis, cited references form the knowledge base[27]. We draw the co-cited network (Figure 5), where the nodes are represented by authors and publication year. The font size is proportional to the centrality. Furthermore, we selected 15 publications with centrality greater than 0.1 as the dataset for full-text analysis in Table 1 of appendix. Among them, articles published by Gao Ling-ling[28] and Larsson Margareta[29], in 2013 and 2009, had 0.37 and 0.33 centrality respectively. Strikingly, Larsson Margareta's research had a burst intensity as high as 10.96 in Table 2 of appendix, which is an essential reference for the study of maternal health in the context of new media, especially in information acquisition behavior[30]. In addition, the two research papers of Lagan Briege $M$ had high burst intensity and long duration 
between 2013 and 2021, which had been widely concerned by researchers.

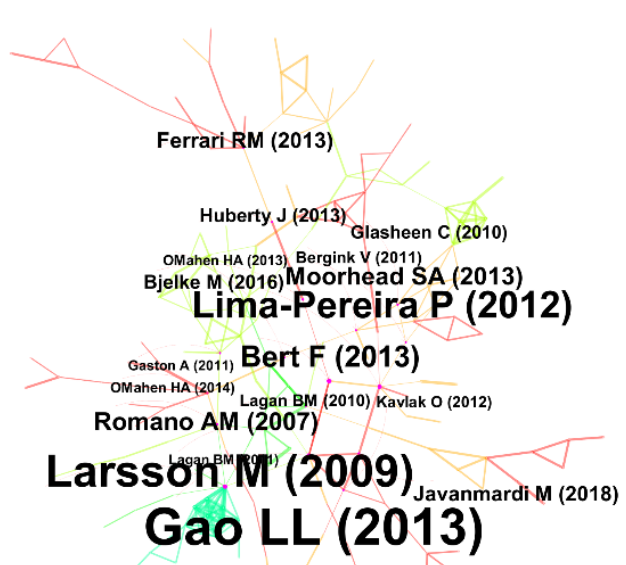

Figure 5. The network of highly cited references

As the number of publications continues to increase, a new paper may change the structure of the existing research network[30]. Structural variation analysis may measure the potential impact on the existing network structure and reveals the mechanism of scientific development, which is also the lack of traditional bibliometrics studies[27]. In the analysis of structural variation, the modularity change rate, the change of inter-cluster connection, and the change of centrality distribution could be used to measure the academic influence. Strikingly, $\Delta \mathrm{M}$ is used in the analysis of CiteSpace by Professor Chen Chaomei, who developed the software and explained the calculation method in detail[31]. In this paper, $\Delta \mathrm{M}$ is also chosen why the higher the value of $\Delta \mathrm{M}$, the greater the potential influence of the new publication on the current network.

In general, among the 2,270 articles, $32.36 \%$ of the articles had a modularity change rate greater than zero. The top 10 articles with the most influence are shown in Table 3 of appendix. Firstly, the paper with the highest was published in 2008. The paper focused on maternal depression, fertility desire, anorexia and other psychosocial factors. Authors studied their influence on maternal health and neonatal diseases, which varied with different medical insurance types and races. Another example is the impact of maternal diet on the health of offspring[32]. At the same time, the influential articles published in the last five years focused on neonatal nutrition. That article confirms that providing health guidance and counseling services to new parents is conducive to forming good eating habits in infants early, effectively preventing obesity and overweight in newborns.

\subsection{Research Frontiers}

As the carrier of science, vocabulary can reveal the development and change of science [33]. This study also displays the topics based on the keywords in each article. 
Table 5 lists the top 10 high frequency keywords and high centrality keywords. At the same time, citation bursts are available, why burst terms better reflect the research frontier[34]. This research drew a burst map of the top 20 terms (Table 6). In the diagram, the blue line represents the entire research period, and the red line represents the duration of the burst, with the beginning and end years of the activity as both ends of the endpoint.

Table 5. Top 10 high-frequency keywords and high centrality keywords

\begin{tabular}{ccccccccc}
\hline \multirow{2}{*}{ Ranking } & \multicolumn{2}{c}{ High-frequency keywords } & & \multicolumn{3}{c}{ High centrality keywords } \\
\cline { 2 - 3 } \cline { 7 - 8 } & Keyword & Frequency & Year & & Keyword & Centrality & Year \\
\hline 1 & pregnancy & 569 & 1998 & & social support & 0.40 & 2003 \\
2 & health & 316 & 2001 & & intervention & 0.38 & 2006 \\
3 & risk & 235 & 2000 & & childhood obesity & 0.31 & 2006 \\
4 & internet & 165 & 2002 & & postpartum & 0.26 & 2006 \\
5 & care & 158 & 2007 & & women & 0.24 & 1998 \\
6 & intervention & 155 & 2008 & & cancer & 0.22 & 2002 \\
7 & mother & 152 & 2004 & & nutrition & 0.21 & 2007 \\
8 & children & 145 & 1999 & & hiv infection & 0.20 & 2006 \\
9 & prevalence & 143 & 2004 & & information & 0.20 & 2005 \\
10 & pregnant & 141 & 2004 & & community & 0.19 & 2005 \\
\hline
\end{tabular}

As can be seen from the Table 6 , the outbreak time generally mainly distributed in 2000 to 2020. Firstly, from 2000 to 2012, "infant" had been the focus of researchers, and the burst intensity of 15.65 is the highest. Meanwhile, topics related to macrosomia, such as "weight," "obesity," and "body mass index," received more attention from 2006 to 2014. Secondly, from 2014 to 2017, research focused more on the "prevention", which provided new ideas for promoting maternal health. In 2015, "Internet" also became a hotspot. Finally, between 2017 and 2020, research started to move out of the comfort zone. Not only had the trend of going back to the source, but the risk factors affecting maternal health had been paid attention to. Meanwhile, health education for pregnant women and psychological problems were also slowly breaking the previous research's bottleneck.

Table 6. Top 20 Keywords with the Strongest Citation Bursts

\begin{tabular}{|c|c|c|c|c|c|c|}
\hline Ranking & Keywords & Year & Strength & Begin & End & 1998 - 2021 \\
\hline 1 & infant & 1998 & 15.65 & 2000 & 2012 & 10 \\
\hline 2 & overweight & 1998 & 8.57 & 2006 & 2014 & 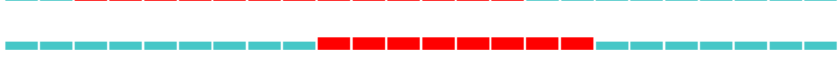 \\
\hline 3 & children & 1998 & 18.22 & 2008 & 2017 & r \\
\hline 4 & mortality & 1998 & 7.31 & 2008 & 2014 & سחصב \\
\hline 5 & exposure & 1998 & 7.18 & 2009 & 2012 & \\
\hline 6 & body mass index & 1998 & 6.00 & 2009 & 2011 & \\
\hline 7 & adolescent & 1998 & 5.52 & 2009 & 2012 & \\
\hline 8 & low birth weight & 1998 & 9.11 & 2010 & 2013 & \\
\hline 9 & perception & 1998 & 8.50 & 2010 & 2014 & \\
\hline 10 & preeclampsia & 1998 & 7.98 & 2011 & 2012 & \\
\hline 11 & $\begin{array}{l}\text { randomized } \\
\text { controlled trial }\end{array}$ & 1998 & 7.03 & 2011 & 2014 & \\
\hline 12 & stress & 1998 & 5.22 & 2012 & 2013 & 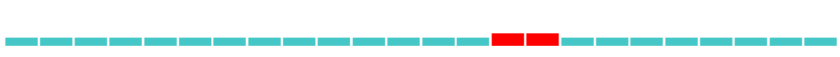 \\
\hline 13 & behavior & 1998 & 10.63 & 2013 & 2017 & 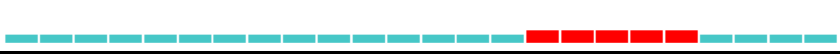 \\
\hline
\end{tabular}




\begin{tabular}{|c|c|c|c|c|c|c|}
\hline Ranking & Keywords & Year & Strength & Begin & End & $1998-2021$ \\
\hline 14 & childbirth & 1998 & 9.13 & 2013 & 2017 & 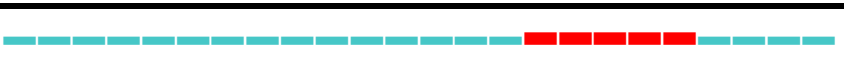 \\
\hline 15 & prevention & 1998 & 15.78 & 2014 & 2017 & \\
\hline 16 & united states & 1998 & 8.25 & 2014 & 2015 & \\
\hline 17 & internet & 1998 & 10.18 & 2015 & 2016 & \\
\hline 18 & attitude & 1998 & 12.28 & 2017 & 2019 & \\
\hline 19 & knowledge & 1998 & 11.10 & 2018 & 2021 & - \\
\hline 20 & mental health & 1998 & 17.80 & 2019 & 2021 & $\mathrm{I}_{-1}$ \\
\hline
\end{tabular}

\subsection{Research Hotspots}

Based on the clustering results of structural variation analysis of cited references, this part aims to analyze the current research hotspots. In the cited references clusters, the present study mainly distributed in three areas: psychological, nutrition, and technology. The research hotspots mainly focus on maternal depressive and fertility intentions, maternal and child nutrition, production equipment, and reproductive technology, the impact of malaria surveillance and the outbreak of the COVID-19. (Figure 6, Figure 7)

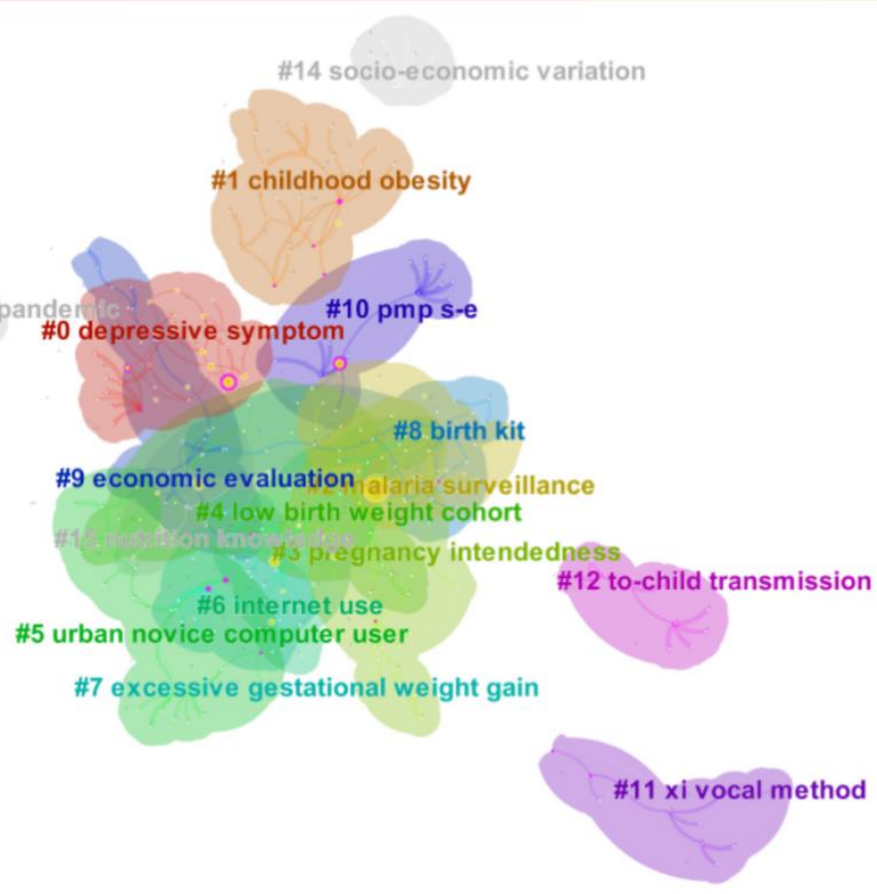

Figure 6. The hotspots cluster 


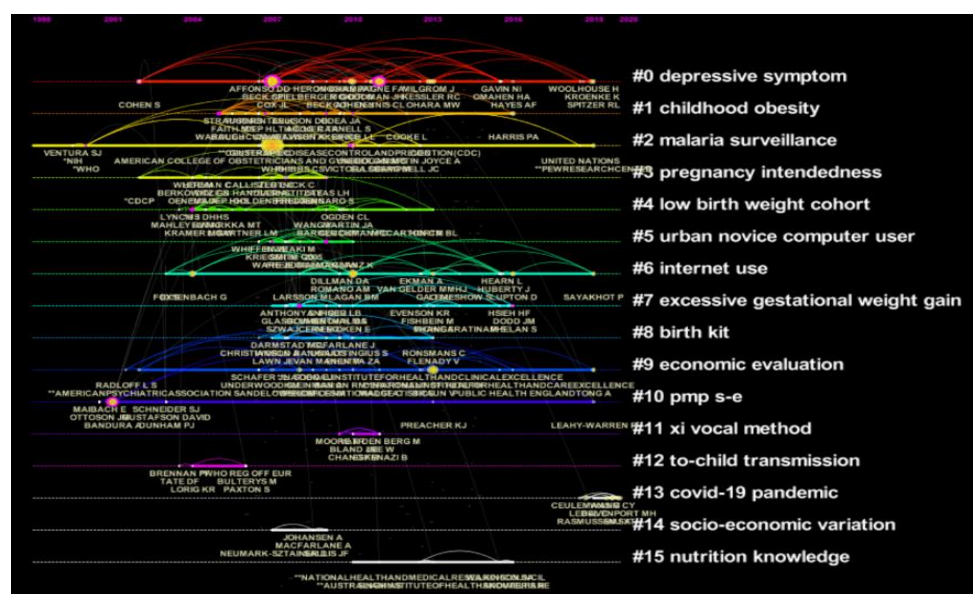

Figure 7. The timeline of hotspots clustering

Firstly, studies on maternal mental health in the new media environment include clusters \#0 and \#3, which lasted from 2001 to 2019. Maternal depression may be appropriately considered a population health problem[35]. This hotspot focuses on postnatal depression, mental health, pregnancy intendedness, maternal psychosocial factors, women's expectations, influencing factors and pain relief. The paper published in 2008 is the most representative, as shown in Figure 8 in appendix. The solid pink line represents the research structure before the paper's publication, while the dotted red line indicates the influence of the paper on the network structure. Obviously, this paper links psychosocial factors such as pregnant women's fertility intention with low birth weight[36]. It is an essential reference for the mental health of pregnant women in the new media environment.

Secondly, studies on maternal and neonatal nutrition in the new media environment include Clusters \#1, \#4, and \#7, but the popularity declined in the past three years. It focused on childhood obesity, food neophobia, maternal feeding style, children's body size, low birth weight cohort, economic factors, excessive gestational weight gain and postpartum weight loss. The article published in 2011 is typical, as shown in Figure 9 in appendix. This article takes cesarean section of pregnant women as the research topic and emphasizes the use and monitoring of computers based on the traditional network structure[37].

Thirdly, research on reproductive technology in the new media environment included clusters \#2, \#5, \#6, \#8, and \#15, and this hotspot lasted the longest. Main keywords including malaria surveillance, technology-based peer support, urban novice computer user, web-based survey, Internet use and safe childbirth. In developed countries, most maternal deaths are due mainly to anesthesia and cesarean section complications, so improved production equipment and technology are also essential to ensure maternal security[38]. This article(Figure 10 in appendix) is published in 2015, with a 13.946 impact factor. And it highlights the clinical manifestation types of neonatal preterm birth syndrome. Therefore, new connections are also being established in clusters \#2, \#3, \#4 and \#8, which significantly impact traditional network architecture[39].

At the same time, in the global context of COVID-19, researchers also began to pay attention to its influence on maternal health, mainly including the COVID-19 pandemic, related factor, web-based cross-sectional study, mental health, developmental outcome, longitudinal cohort study, COVID-19 lockdown. COVID-19 could lead to severe morbidity and perinatal death in pregnant women, so there is a need 
for enhanced surveillance to avoid maternal and even neonatal infection[40,41].

\section{Discussion}

\subsection{Principal Results}

In this study, we are aiming to investigate the impact of the new media environment on maternal health and the hotspots arising in academic over a period of nearly 20 years, then vividly presenting them using a scientometric approach. Our findings show that the number of publications and citations has grown substantially since 2008 , and the increase is particularly notable by 2020 . However, there is a clear difference in the distribution, dominant power of studies is the United States, and University of Toronto also occupies an important position. The reason may be that while maternal mortality is descending globally, the United States is ascending continually[39]. Particularly from 2008 to 2009, maternal mortality under the age of 40 per 100000 population had increased $25 \%$ [42], which may have attracted national and academic attentions. Furthermore, the 2008 US election campaign has demonstrated the important role new media plays in information transmission[43]. It has been speculated that, internationally, research on new media has also set the 2008 demarcation point, after which it has begun to grow significantly[44]. Another finding indicates that mental health emerged in 2001 and gradually leveled off in 2019. This may be due to the fact that the new media environment is a double-edged sword. Although a large amount of redundant information may be misleading for the pregnant woman, social software such as Facebook or Wechat make communication more convenient and beneficial for alleviating antenatal or postpartum maternal anxiety. To illustrate, the implementation of the Chinese two-child policy did not produce the desired effect[45,46] why governments also needs to relieve maternal anxiety or depression and improve childbearing intentions [47]. Interestingly, articles or authors that learn the critical node articles and innovate have a high modularity change rate, positively influencing research network. So it is critical to establish new connections based on the existing research network structure.

\subsection{Past Studies and Future Directions}

Maternal health as an important strategy to improve social health has attracted much attention from the international community. Compatible with the ever-increasing number of publications, an increasing number of publications have analysed the current research status on maternal health with scientific methods. And the development of new media has not only made people's lives more convenient, but also permeated in various fields, of which maternal health is one. However, publications analyzing maternal health in new media environment based on an international perspective are still lacking. Similar to the results of this study, a lancet commission reported that challenges in improving maternal and neonatal health in China are focused on delivery safety, maternal and neonatal nutrition, mental health, and stillbirth[48]. Studies about the United States shows that maternal research gradually shifted from physical health and weight to mental health and satisfaction, and conforming to the predictions that depression is one of the critical factors of the global burden of disease[45,46]. This research also finds hotspots, such as neonatal nutrition and the resulting unhealthy conditions(low birth weight or macrosomia). A recent trial study in Timor Leste also 
have shown that maternal food intake affects a child's nutrition and weight[49]. Furthermore, preventing excessive weight gain in mothers and adjusting post-weaning diets could help reduce childhood obesity worldwide[50].

The most distinctive feature of this study is that based on an international perspective, we use structural variation analysis to explore the current research hotspots. And in the analysis of highly cited literatures, modularity change rate was used to measure the potential impact of articles, which is different from previous scientometrics analysis. On the other hand, there are several limitations, such as the quality of data and the stability of software runs, but it is also our future research direction. It is also possible that databases such as PubMed and Scopus may have higher quality publications, but due to the limitation of study manpower, we only selected Web of Science to collect publications and used CiteSpace to removed duplicates, which may have biased our analysis results. To address this issue, future research would like to explore appropriate seed articles, and use the cascade extension function to screen out high quality publications collection[27]. Besides, we will also verify if the parameters change, the study will get the same conclusion, or if there is a final threshold that makes the result stable. Despite these limitations, this study provides several key insights to understand the research on maternal health in the new media environment and important approaches in future research.

\section{Conclusions}

This scientometrics study systematically searched articles in the core database of Web of Science, the findings show a rapid increase since 2008 in the number of publiactions on maternal health in the new media environment. However, in terms of countries, institutions as well as high impact articles, the research power is mainly distributed in North America. Specifically, the United States played a leading role with a comparatively large amount of publications, while the University of Toronto is better than other institutions. Maternal depression, maternal and infant nutrition, low birth weight, macrosomia, and delivery technique and facilities had received extensive attention from the scientific research personnel. Future research perspectives should also shift from physiological disorders to mental health and explore the potential of advanced technologies in improving maternal health. Besides, this paper also compensate gaps in research method and providing valuable information for researchers to find their research directions.

Author Contributions: Conceptualization, Shangfeng Tang; Data processing, Yinghua Xie; Formal modification, Dong Lang; Methodology, Yinghua Xie; Writing - original draft, Yinghua Xie; Supervision, Chengxu Long. All authors have read and agreed to the published version of the manuscript.

Funding: This research received no external funding.

Data Availability Statement: For data availability, please contact the authors.

Conflicts of Interest: The authors declare no conflict of interest for this article. 


\section{Appendix}

Table 1. Highly cited references (Sort by centrality)

\begin{tabular}{|c|c|c|c|c|}
\hline Ranking & Centrality & Author & Year & Title \\
\hline 1 & 0.37 & $\begin{array}{l}\text { Gao Ling- } \\
\text { ling }\end{array}$ & 2013 & $\begin{array}{l}\text { Internet use by Chinese women seeking pregnancy- } \\
\text { related information }\end{array}$ \\
\hline 2 & 0.33 & $\begin{array}{l}\text { Larsson } \\
\text { Margareta }\end{array}$ & 2009 & $\begin{array}{l}\text { A descriptive study of the use of the Internet by } \\
\text { women seeking pregnancy-related information }\end{array}$ \\
\hline 3 & 0.27 & $\begin{array}{l}\text { Lima- } \\
\text { Pereira } \\
\text { Patricia }\end{array}$ & 2012 & $\begin{array}{l}\text { Use of the Internet as a source of health information } \\
\text { amongst participants of antenatal classes }\end{array}$ \\
\hline 4 & 0.22 & $\begin{array}{c}\text { Bert } \\
\text { Fabrizio }\end{array}$ & 2013 & $\begin{array}{l}\text { Pregnancy e-health: a multicenter Italian cross- } \\
\text { sectional study on internet use and decision-making } \\
\text { among pregnant women }\end{array}$ \\
\hline 5 & 0.18 & $\begin{array}{l}\text { Moorhead } \\
\text { S. Anne }\end{array}$ & 2013 & $\begin{array}{l}\text { A New Dimension of Health Care: Systematic } \\
\text { Review of the Uses, Benefits, and Limitations of } \\
\text { Social Media for Health Communication }\end{array}$ \\
\hline 6 & 0.18 & $\begin{array}{l}\text { Romano } \\
\text { Amy M }\end{array}$ & 2007 & $\begin{array}{l}\text { A Changing Landscape: Implications of Pregnant } \\
\text { Women's Internet Use for Childbirth Educators }\end{array}$ \\
\hline 7 & 0.16 & $\begin{array}{c}\text { Ferrari } \\
\text { Renee M }\end{array}$ & 2013 & $\begin{array}{l}\text { A qualitative study of women's perceptions of } \\
\text { provider advice about diet and physical activity } \\
\text { during pregnancy }\end{array}$ \\
\hline 8 & 0.15 & $\begin{array}{l}\text { Javanmardi } \\
\text { Marzieh }\end{array}$ & 2018 & $\begin{array}{l}\text { Internet Usage among Pregnant Women for Seeking } \\
\text { Health Information: A Review Article }\end{array}$ \\
\hline 9 & 0.14 & $\begin{array}{l}\text { Huberty } \\
\text { Jennifer }\end{array}$ & 2013 & $\begin{array}{l}\text { Describing the Use of the Internet for Health, Physical } \\
\text { Activity, and Nutrition Information in Pregnant } \\
\text { Women }\end{array}$ \\
\hline 10 & 0.14 & $\begin{array}{l}\text { Bjelke } \\
\text { Maria }\end{array}$ & 2016 & $\begin{array}{l}\text { Using the Internet as a source of information during } \\
\text { pregnancy - A descriptive cross-sectional study in } \\
\text { Sweden }\end{array}$ \\
\hline 11 & 0.13 & $\begin{array}{l}\text { Glasheen } \\
\text { Cristie }\end{array}$ & 2010 & $\begin{array}{l}\text { A systematic review of the effects of postnatal } \\
\text { maternal anxiety on children }\end{array}$ \\
\hline 12 & 0.12 & $\begin{array}{l}\text { Lagan } \\
\text { Briege M }\end{array}$ & 2010 & $\begin{array}{l}\text { Online Purchasing of Isotretinoin: E-Pharmacies } \\
\text { Provision of Safety Information }\end{array}$ \\
\hline 13 & 0.12 & $\begin{array}{l}\text { Bergink } \\
\text { Veerle }\end{array}$ & 2011 & $\begin{array}{l}\text { Validation of the Edinburgh Depression Scale during } \\
\text { pregnancy }\end{array}$ \\
\hline 14 & 0.11 & $\begin{array}{l}\text { O'Mahen } \\
\text { H. A. }\end{array}$ & 2014 & $\begin{array}{l}\text { Netmums: a phase II randomized controlled trial of a } \\
\text { guided Internet behavioural activation treatment for } \\
\text { postpartum depression }\end{array}$ \\
\hline 15 & 0.11 & $\begin{array}{c}\text { Kavlak } \\
\text { Oya }\end{array}$ & 2012 & $\begin{array}{l}\text { Pregnant women's use of the internet in relation to } \\
\text { their pregnancy in Izmir, Turkey }\end{array}$ \\
\hline
\end{tabular}

Table 2. Top 25 References with the Strongest Citation Bursts

\begin{tabular}{|c|c|c|c|c|c|c|}
\hline Ranking & Title & Year & Strength & Begin & End & 1998 - 2021 \\
\hline 1 & $\begin{array}{l}\text { A descriptive study of the } \\
\text { use of the Internet by } \\
\text { women seeking } \\
\text { pregnancy-related } \\
\text { information }\end{array}$ & 2009 & 10.96 & 2009 & 2018 & \\
\hline 2 & $\begin{array}{l}\text { Maternal mortality for } \\
181 \text { countries, 1980- } \\
\text { 2008: a systematic } \\
\text { analysis of progress } \\
\text { towards Millennium } \\
\text { Development Goal 5 }\end{array}$ & 2010 & 3.98 & 2010 & 2015 & \\
\hline 3 & $\begin{array}{l}\text { Developmental and } \\
\text { epigenetic pathways to }\end{array}$ & 2008 & 3.86 & 2010 & 2012 & \\
\hline
\end{tabular}




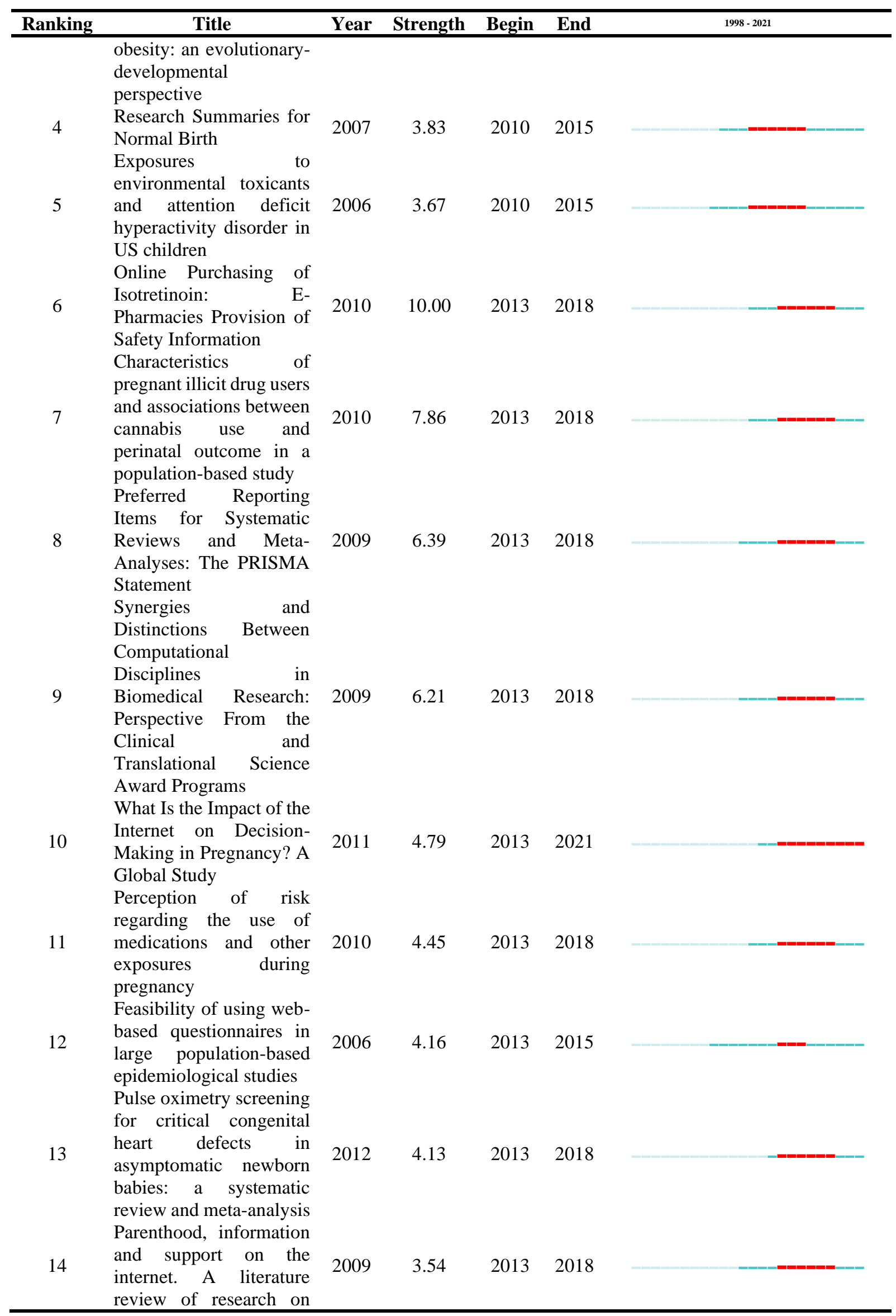




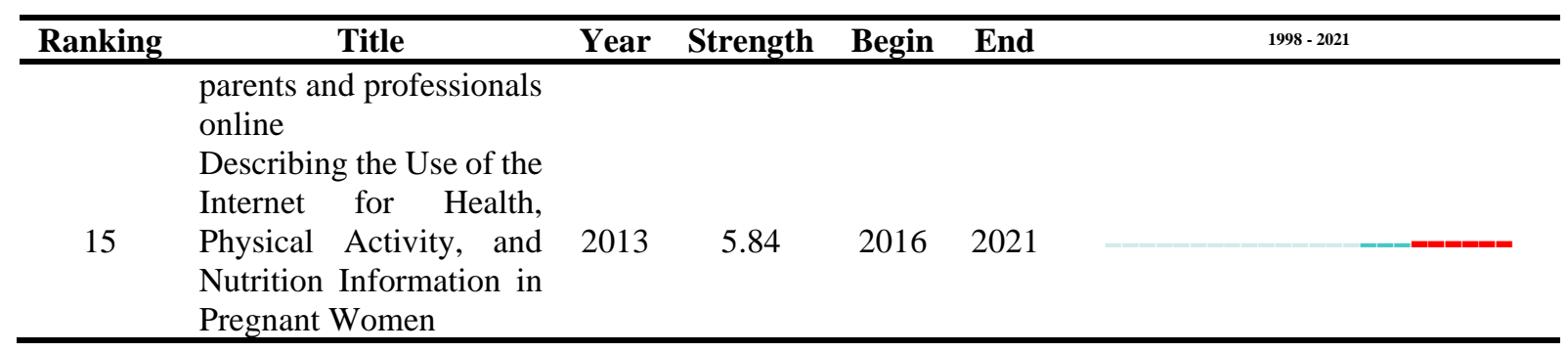

Table 3. Top 15 papers with potential transformational significance

\begin{tabular}{|c|c|c|c|}
\hline Ranking & $\Delta \mathbf{M}$ & Year & Citing articles \\
\hline 1 & 98.30 & 2008 & $\begin{array}{l}\text { Hostility and anomie: Links to preterm delivery subtypes and ambulatory } \\
\text { blood pressure at mid-pregnancy }\end{array}$ \\
\hline 2 & 95.54 & 2011 & $\begin{array}{l}\text { Artificially maintained scientific controversies, the construction of } \\
\text { maternal choice and caesarean section rates }\end{array}$ \\
\hline 3 & 95.04 & 2012 & $\begin{array}{l}\text { Impact of Perinatal Different Intrauterine Environments on Child Growth } \\
\text { and Development in the First Six Months of Life--IVAPSA Birth Cohort: } \\
\text { rationale, design, and methods. }\end{array}$ \\
\hline 4 & 94.26 & 2015 & $\begin{array}{l}\text { The Distribution of Clinical Phenotypes of Preterm Birth Syndrome } \\
\text { Implications for Prevention }\end{array}$ \\
\hline 5 & 94.26 & 2013 & $\begin{array}{l}\text { What Kinds of Website and Mobile Phone-Delivered Physical Activity } \\
\text { and Nutrition Interventions Do Middle-Aged Men Want? }\end{array}$ \\
\hline 6 & 93.93 & 2011 & $\begin{array}{l}\text { Maternal health behaviours during pregnancy in an Irish obstetric } \\
\text { population and their associations with socio-demographic and infant } \\
\text { characteristics }\end{array}$ \\
\hline 7 & 93.62 & 2007 & $\begin{array}{l}\text { Addressing malnutrition in young children in South Africa. Setting the } \\
\text { national context for paediatric food-based dietary guidelines }\end{array}$ \\
\hline 8 & 93.19 & 2009 & $\begin{array}{l}\text { Staying Home to Give Birth: Why Women in the United States Choose } \\
\text { Home Birth }\end{array}$ \\
\hline 9 & 92.63 & 2017 & $\begin{array}{l}\text { Early food for future health: a randomized controlled trial evaluating the } \\
\text { effect of an eHealth intervention aiming to promote healthy food habits } \\
\text { from early childhood }\end{array}$ \\
\hline 10 & 92.56 & 2011 & $\begin{array}{l}\text { Heading Into Fatherhood-Nervously: Support for Fathering From Online } \\
\text { Dads }\end{array}$ \\
\hline 11 & 92.56 & 2010 & $\begin{array}{l}\text { Does lower birth order amplify the association between high } \\
\text { socioeconomic status and central adiposity in young adult Filipino males? }\end{array}$ \\
\hline 12 & 92.19 & 2015 & $\begin{array}{l}\text { Innovative approaches for improving maternal and newborn health - A } \\
\text { landscape analysis }\end{array}$ \\
\hline 13 & 90.89 & 2010 & $\begin{array}{l}\text { Risk factors for rapid weight gain in preschool children: findings from a } \\
\text { UK-wide prospective study }\end{array}$ \\
\hline 14 & 90.70 & 2012 & $\begin{array}{l}\text { Adherence to antiretroviral therapy during and after pregnancy in low- } \\
\text { income, middle-income, and high-income countries: a systematic review } \\
\text { and meta-analysis }\end{array}$ \\
\hline 15 & 90.70 & 2012 & $\begin{array}{l}\text { Universal Prevention is Associated with Lower Prevalence of Fetal } \\
\text { Alcohol Spectrum Disorders in Northern Cape, South Africa: A } \\
\text { Multicentre Before-After Study }\end{array}$ \\
\hline
\end{tabular}

$\Delta \mathrm{M}$ : Modularity change rate 


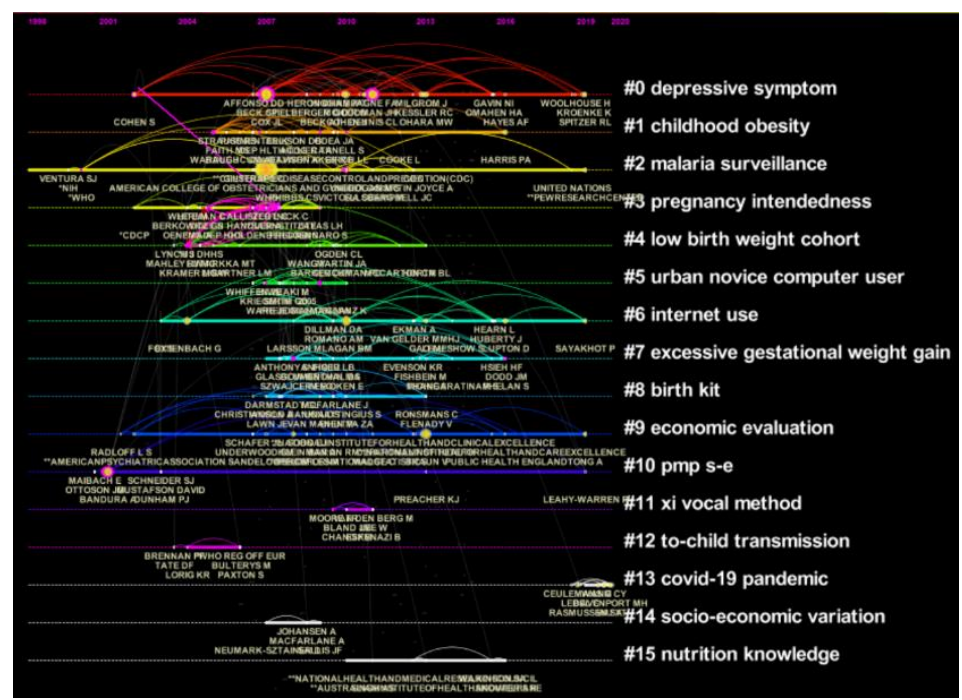

Figure 8. Structural variation arising from representative literature on maternal mental health

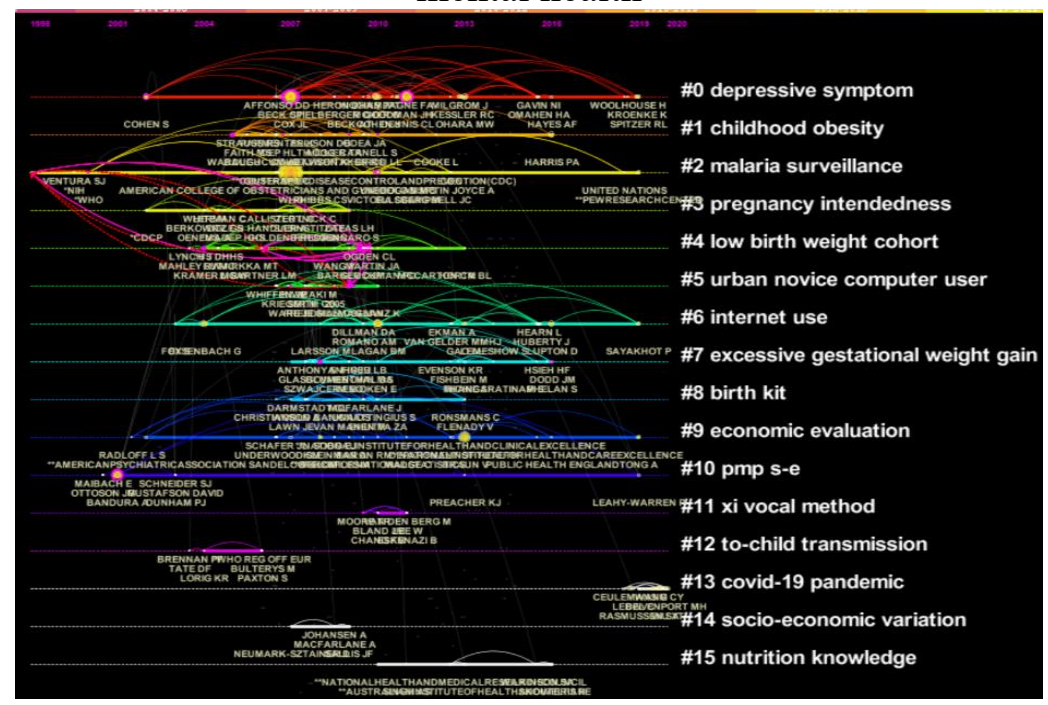

Figure 9. Structural variation arising from representative literature on maternal and neonatal nutrition

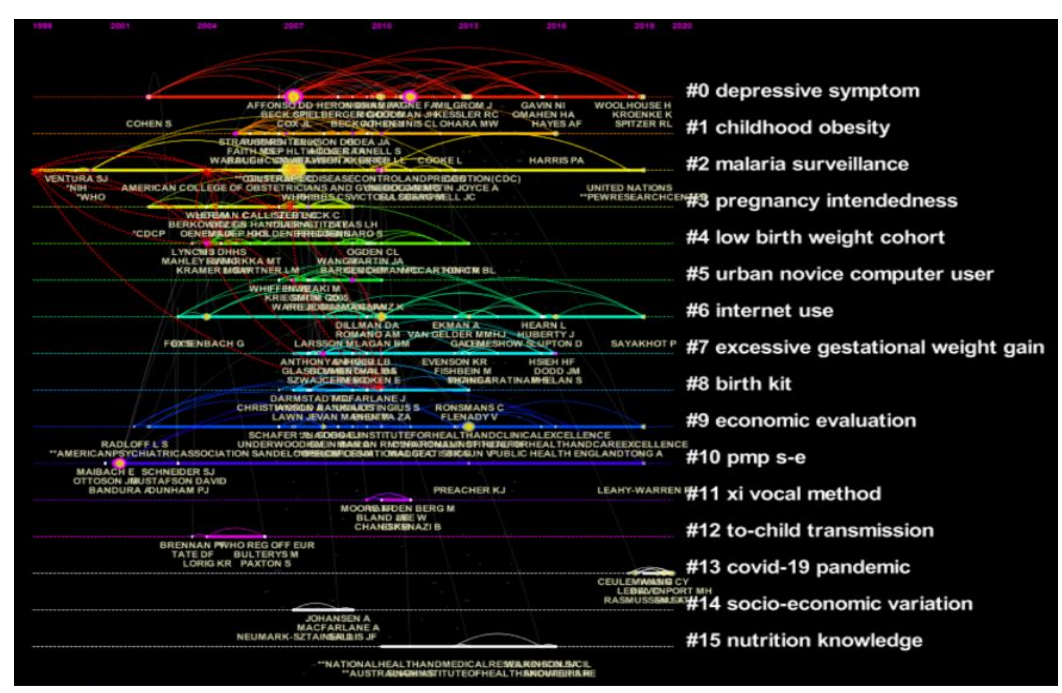


Figure 10. Structural variations arising from representative literature on reproductive technology and devices 


\section{Reference}

1. Duley, L. The Global Impact of Pre-Eclampsia and Eclampsia. Semin. Perinatol. 2009, 33, 130-137, doi:10.1053/j.semperi.2009.02.010.

2. Lozano, R.; Naghavi, M.; Foreman, K.; Lim, S.; Shibuya, K.; Aboyans, V.; Abraham, J.; Adair, T.; Aggarwal, R.; Ahn, S.Y.; et al. Global and Regional Mortality from 235 Causes of Death for 20 Age Groups in 1990 and 2010: A Systematic Analysis for the Global Burden of Disease Study 2010. The Lancet 2012, 380, 2095-2128, doi:10.1016/S0140-6736(12)61728-0.

3. Boudreaux, C.; Chanthala, P.; Lindelow, M. Assessing the Elimination of User Fees for Delivery Services in Laos. PLOS ONE 2014, 9, e89784, doi:10.1371/journal.pone.0089784.

4. Witter, S.; Khadka, S.; Nath, H.; Tiwari, S. The National Free Delivery Policy in Nepal: Early Evidence of Its Effects on Health Facilities. Health Policy Plan. 2011, 26, ii84-ii91, doi:10.1093/heapol/czr066.

5. Zhou, D.; Zhou, Z.; Yang, C.; Ji, L.; Ghose, B.; Tang, S. Sociodemographic Characteristics Associated with the Utilization of Maternal Health Services in Cambodia. BMC Health Serv. Res. 2020, 20, 781, doi:10.1186/s12913-020-05652-1.

6. Yang, X.; Tang, S.; Yamey, G.; Qian, X. Strengthening Maternal and Child Health in China: Lessons from Transforming Policy Proposals into Action. Biosci. Trends 2018 , 12, 211-214, doi:10.5582/bst.2018.01034.

7. undefined; Jt, B.; J, B.; Y, K.; H, A.; Cg, V. Mind the Gap: Equity and Trends in Coverage of Maternal, Newborn, and Child Health Services in 54 Countdown Countries. Lancet Lond. Engl. 2008, 371, 1259-1267, doi:10.1016/s0140-6736(08)60560-7.

8. Victora, C.G.; Aquino, E.M.; do Carmo Leal, M.; Monteiro, C.A.; Barros, F.C.; Szwarcwald, C.L. Maternal and Child Health in Brazil: Progress and Challenges. The Lancet 2011, 377, 1863-1876, doi:10.1016/S0140-6736(11)60138-4.

9. Nishimwe, C.; Mchunu, G.G.; Mukamusoni, D. Community- Based Maternal and Newborn Interventions in Africa: Systematic Review. J. Clin. Nurs. n/a, doi:10.1111/jocn. 15737.

10. Çalışkan, Z.; Kılıç, D.; Öztürk, S.; Atılgan, E. Equity in Maternal Health Care Service Utilization: A Systematic Review for Developing Countries. Int. J. Public Health 2015, 60, 815-825, doi:10.1007/s00038-015-0711-x.

11. Dahab, R.; Sakellariou, D. Barriers to Accessing Maternal Care in Low Income Countries in Africa: A Systematic Review. Int. J. Environ. Res. Public. Health 2020, 17, 4292, doi:10.3390/ijerph17124292.

12. Kingston, D.; Tough, S.; Whitfield, H. Prenatal and Postpartum Maternal Psychological Distress and Infant Development: A Systematic Review. Child Psychiatry Hum. Dev. 2012, 43, 683-714, doi:10.1007/s10578-012-0291-4. 
13. Yang, F.-C.; Lee, A.J.T.; Kuo, S.-C. Mining Health Social Media with Sentiment Analysis. J. Med. Syst. 2016, 40, 236, doi:10.1007/s10916-016-0604-4.

14. World Internet Users Statistics and 2021 World Population Stats Available online: https://www.internetworldstats.com/stats.htm (accessed on 9 July 2021).

15. Moorhead, S.A.; Hazlett, D.E.; Harrison, L.; Carroll, J.K.; Irwin, A.; Hoving, C. A New Dimension of Health Care: Systematic Review of the Uses, Benefits, and Limitations of Social Media for Health Communication. J. Med. Internet Res. 2013, 15, e1933, doi:10.2196/jmir.1933.

16. Zhang, T.; Li, H.; Zhang, X.; Yu, F.; Zhao, K. The Evolution of Chinese New Media Research in 1998-2017 — An Analysis Based on Science Mapping by CiteSpace. $J$. China Stud. 2019, 22, 135-153.

17. Ward, V.C.; Raheel, H.; Weng, Y.; Mehta, K.M.; Dutt, P.; Mitra, R.; Sastry, P.; Godfrey, A.; Shannon, M.; Chamberlain, S.; et al. Impact of MHealth Interventions for Reproductive, Maternal, Newborn and Child Health and Nutrition at Scale: BBC Media Action and the Ananya Program in Bihar, India. J. Glob. Health 2020, 10, 021005, doi:10.7189/jogh.10.021005.

18. Tang, S.; Yin, X.; Wang, G.; Lu, X.; Lu, T. Single Titanium-Oxide Species Implanted in 2D g-C3N4 Matrix as a Highly Efficient Visible-Light CO2 Reduction Photocatalyst. Nano Res. 2019, 12, 457-462, doi:10.1007/s12274-018-2240-4.

19. Wang, Y.; Etowa, J.; Ghose, B.; Tang, S.; Ji, L.; Huang, R. Association Between Mass Media Use and Maternal Healthcare Service Utilisation in Malawi. J. Multidiscip. Healthc. 2021, 14, 1159-1167, doi:10.2147/JMDH.S304078.

20. Hookway, N.; Elmer, S.; Frandsen, M. Risk, Morality and Emotion: Social Media Responses to Pregnant Women Who Smoke. Health Risk Soc. 2017, 19, 246-259, doi:10.1080/13698575.2017.1385731.

21. Ping, Q.; He, J.; Chen, C. How Many Ways to Use CiteSpace? A Study of User Interactive Events over 14 Months. J. Assoc. Inf. Sci. Technol. 2017, 68, 1234-1256, doi:10.1002/asi.23770.

22. A Comprehensive Bibliometric Analysis of Uncertain Group Decision Making from 1980 to 2019 - $\quad$ ScienceDirect Available online: https://www.sciencedirect.com/science/article/pii/S0020025520308033?via\%3Dihub (accessed on 12 October 2021).

23. Randomized Trials, Meta-Analyses, and Systematic Reviews: Using Examples from Rheumatology - ScienceDirect.

24. Chen, C. Science Mapping: A Systematic Review of the Literature. J. Data Inf. Sci. 2017, 2, 1-40, doi:10.1515/jdis-2017-0006.

25. Chen, C.; Song, M.; Heo, G.E. A Scalable and Adaptive Method for Finding Semantically Equivalent Cue Words of Uncertainty. J. Informetr. 2018, 12, 158-180, doi:10.1016/j.joi.2017.12.004.

26. Kleinberg, J. Bursty and Hierarchical Structure in Streams. Data Min. Knowl. Discov. 2003, 7, 373-397, doi:10.1023/A:1024940629314. 
27. Hou, J.; Yang, X.; Chen, C. Measuring Researchers' Potential Scholarly Impact with Structural Variations: Four Types of Researchers in Information Science (1979-2018). PLOS ONE 2020, 15, e0234347, doi:10.1371/journal.pone.0234347.

28. Gao, L.; Larsson, M.; Luo, S. Internet Use by Chinese Women Seeking PregnancyRelated Information. Midwifery 2013, 29, 730-735, doi:10.1016/j.midw.2012.07.003.

29. Larsson, M. A Descriptive Study of the Use of the Internet by Women Seeking Pregnancy-Related Information. Midwifery 2009, 25, 14-20, doi:10.1016/j.midw.2007.01.010.

30. Chen, C. Predictive Effects of Structural Variation on Citation Counts. J. Am. Soc. Inf. Sci. Technol. 2012, 63, 431-449, doi:10.1002/asi.21694.

31. Hou, J.; Yang, X.; Chen, C. Measuring Researchers' Potential Scholarly Impact with Structural Variations: Four Types of Researchers in Information Science (1979-2018). Plos One 2020, 15, e0234347, doi:10.1371/journal.pone.0234347.

32. Wolff, G.L.; Kodell, R.L.; Moore, S.R.; Cooney, C.A. Maternal Epigenetics and Methyl Supplements Affect Agouti Gene Expression in Avy/a Mice. FASEB J. 1998, 12, 949-957, doi:10.1096/fasebj.12.11.949.

33. Courtial, J.P. Comments on Leydesdorff's Article. J. Am. Soc. Inf. Sci. 1998, 49, 98-98, doi:10.1002/(SICI)1097-4571(199801)49:1<98::AID-ASI14>3.0.CO;2-1.

34. Liu, J.-W.; Huang, L.-C. Detecting and Visualizing Emerging Trends and Transient Patterns in Fuel Cell Scientific Literature. In Proceedings of the 2008 4th International Conference on Wireless Communications, Networking and Mobile Computing; October 2008; pp. 1-4.

35. Meaney, M.J. Perinatal Maternal Depressive Symptoms as an Issue for Population Health. Am. J. Psychiatry 2018, 175, 1084-1093, doi:10.1176/appi.ajp.2018.17091031. 36. Hostility and Anomie: Links to Preterm Delivery Subtypes and Ambulatory Blood Pressure at Mid-Pregnancy. Soc. Sci. Med. 2008, 66, 1310-1321, doi:10.1016/j.socscimed.2007.11.039.

37. Sarda, G. Artificially Maintained Scientific Controversies, the Construction of Maternal Choice and Caesarean Section Rates. Soc. Theory Health 2011, 9, 166-182, doi:10.1057/sth.2010.12.

38. Khan, K.S.; Wojdyla, D.; Say, L.; Gülmezoglu, A.M.; Van Look, P.F. WHO Analysis of Causes of Maternal Death: A Systematic Review. The Lancet 2006, 367, 1066-1074, doi:10.1016/S0140-6736(06)68397-9.

39. Barros, F.C.; Papageorghiou, A.T.; Victora, C.G.; Noble, J.A.; Pang, R.; Iams, J.; Cheikh Ismail, L.; Goldenberg, R.L.; Lambert, A.; Kramer, M.S.; et al. The Distribution of Clinical Phenotypes of Preterm Birth Syndrome: Implications for Prevention. JAMA Pediatr. 2015, 169, 220-229, doi:10.1001/jamapediatrics.2014.3040.

40. Zaigham, M.; Andersson, O. Maternal and Perinatal Outcomes with COVID-19: A Systematic Review of 108 Pregnancies. Acta Obstet. Gynecol. Scand. 2020, 99, 823829, doi:10.1111/aogs. 13867.

41. Schwartz, D.A. An Analysis of 38 Pregnant Women With COVID-19, Their 
Newborn Infants, and Maternal-Fetal Transmission of SARS-CoV-2: Maternal Coronavirus Infections and Pregnancy Outcomes. Arch. Pathol. Lab. Med. 2020, 144, 799-805, doi:10.5858/arpa.2020-0901-SA.

42. Chinn, J.J.; Eisenberg, E.; Artis Dickerson, S.; King, R.B.; Chakhtoura, N.; Lim, I.A.L.; Grantz, K.L.; Lamar, C.; Bianchi, D.W. Maternal Mortality in the United States: Research Gaps, Opportunities, and Priorities. Am. J. Obstet. Gynecol. 2020, 223, 486492.e6, doi:10.1016/j.ajog.2020.07.021.

43. Hendrix, G.J. The Roles of Social Media in 21st Century Populisms: US Presidential Campaigns. Teknokultura Rev. Cult. Digit. Mov. Soc. 2019, 16, 1-10, doi:10.5209/TEKN.63098.

44. Caquard, S. Cartography II: Collective Cartographies in the Social Media Era. Prog. Hum. Geogr. 2014, 38, 141-150, doi:10.1177/0309132513514005.

45. Victoria, G.C.; Adair, L.; Fall, C.; Challal, P.; Ritcher, L.; Sachdev, H. Maternal and Child Undernutrition 2 Maternal and Chils Undernutrition: Consequences For Adult Health and Human Capital. Lamcet Community Health 2008, 55, 394-8.

46. Li, H.; Xue, M.; Hellerstein, S.; Cai, Y.; Gao, Y.; Zhang, Y.; Qiao, J.; Blustein, J.; Liu, J. Association of China's Universal Two Child Policy with Changes in Births and Birth Related Health Factors: National, Descriptive Comparative Study. BMJ 2019, 366, 14680, doi:10.1136/bmj.14680.

47. Campbell, O.M.; Graham, W.J. Strategies for Reducing Maternal Mortality: Getting on with What Works. The Lancet 2006, 368, 1284-1299, doi:10.1016/S01406736(06)69381-1.

48. Qiao, J.; Wang, Y.; Li, X.; Jiang, F.; Zhang, Y.; Ma, J.; Song, Y.; Ma, J.; Fu, W.; Pang, R.; et al. A Lancet Commission on 70 Years of Women's Reproductive, Maternal, Newborn, Child, and Adolescent Health in China. The Lancet 2021, 397, 2497-2536, doi:10.1016/S0140-6736(20)32708-2.

49. Yaya, S.; Wang, R.; Tang, S.; Ghose, B. Intake of Supplementary Food during Pregnancy and Lactation and Its Association with Child Nutrition in Timor Leste. PeerJ 2018, 6, e5935, doi:10.7717/peerj.5935.

50. Deckelbaum, R.J.; Williams, C.L. Childhood Obesity: The Health Issue. Obes. Res. 2001, 9, 239S-243S, doi:10.1038/oby.2001.125. 